\title{
UMA PONTE PARA O PASSADO: COLONIALIDADE E MINERAÇÃO NO BRASIL E NO PERU (1990-2018)
}

\author{
Guilherme da Silva Monteiro ${ }^{1}$
} Vanderlei Vazelesk Ribeiro ${ }^{2}$

\begin{abstract}
RESUMO
Neste trabalho, partindo das reflexões de Enrique Dussel e Horácio Machado Aráoz, buscamos analisar a relação entre colonialidade e mineração no Brasil e no Peru, a partir da década de 1990, no momento que o neoliberalismo impacta os dois países. Baseado na reflexão de Aníbal Quijano, e de alguns autores brasileiros pensaremos o impacto de megaprojetos de mineração, no Brasil e no Peru, percebendo em uma clave gramsciana a relação entre repressão e consenso que se desenvolve para importar tais projetos em ambas Amazônias e nos Andes Peruanos. Por fim, identificamos os elementos de colonialidade nos projetos Volta Grande do Xingu e Conga.
\end{abstract}

Palavras-chave: Colonialidade. Mineração. Grandes Projetos. História Comparada da América Latina.

\section{A BRIDGE TO THE PAST: COLONIALITY AND MINING IN BRAZIL AND PERU (1990-2018)}

\begin{abstract}
In this paper, based on the reflections of Enrique Dussel and Horácio Machado Aráoz, we seek to analyze the relationship between coloniality and mining in Brazil and Peru, from the 1990s onwards, when neoliberalism had an impact on both countries. Based on the reflection of Aníbal Quijano, and some Brazilian authors, we will think about the impact of mining megaprojects in Brazil and Peru, realizing in a Gramscian key the relationship between repression and consensus that develops to import such projects in both the Amazon and in the Peruvian Andes. Finally, we identify the elements of coloniality in the Volta Grande do Xingu and Conga projects.
\end{abstract}

Keywords: Coloniality. Mining. Large Projects. Latin America 's Comparativa History.

Data de submissão: 27.07 .2021

Data de aprovação: 19.11 .2021

\section{INTRODUÇÃO}

O sistema-mundo que foi constituído a partir de 1492, início da Conquista da América, tem como base a mineração transnacional moderna. Esse fenômeno, que tem como marco fundador o boom da mineração na cidade de Potosí (Bolívia), estabeleceu a base material para o desenvolvimento comercial que culminou no advento da sociedade capitalista. Potosí cresceu muito rapidamente, chegando a contar com mais de sessenta mil mitayos, ${ }^{3}$ que foram explorados exaustivamente. Foi esse trabalho de exploração da natureza e da mão de obra nativa

\footnotetext{
${ }^{1}$ Mestrando em História Social pelo Programa de Pós-Graduação em História da Universidade Federal do Estado do Rio de Janeiro (UNIRIO). Email:guilherme.monteiro@edu.unirio.br.

${ }^{2}$ Doutor em História pela Universidade Federal Fluminense (UFF). Professor de História da América Latina da Universidade Federal do Estado do Rio de Janeiro (UNIRIO). E-mail: vvazelesk@ gmail.com.

${ }^{3}$ Membros das comunidades indígenas, que eram obrigadas a ceder uma porcentagem de seus habitantes para trabalharem nas minas e nas plantações espanholas. Era um trabalho forçado, apesar de remunerado, e provocava o deslocamento de grandes contingentes populacionais para outras regiões.
} 
que marcou o lugar de "Nuestra América" no sistema centro-periferia ${ }^{4}$ que se instaurou. O filósofo argentino Enrique $\operatorname{Dussel}^{5}(2004$, p.204) argumenta que a grande quantidade de metais preciosos (ouro e prata) extraídos das colônias, as terras disponíveis para plantio, a força de trabalho dos povos originários e de africanos escravizados, assim como os inovadores descobrimentos científicos, possibilitaram nesse momento que a centralidade geopolítica e geoeconômica passasse a ser desempenhada pela Europa ocidental, desbancando assim o Oriente. Em outras palavras, foi a Conquista da América e a superexploração de seus recursos naturais e humanos que permitiram aos europeus a consolidação como força hegemônica dentro do sistema-mundo moderno.

O início da colonização na América Latina foi feito com base na procura por metais preciosos, tendo em Potosí sua maior descoberta, na América Espanhola os principais momentos da mineração são nos séculos XVI e XVII. Já a América Portuguesa tem seu auge no século XVIII, sendo descoberto o ouro apenas após a exploração profunda de seu território. apesar da importância adquirida pela atividade mineira após a descoberta das jazidas em Minas Gerais, Goiás e Mato Grosso, a mineração passou rapidamente a decadência no curto espaço de tempo de cem anos. "A maldição da abundância" termo cunhado pelo economista equatoriano Alberto Acosta ${ }^{6}$ (2009, p.11) exemplifica a situação dessas nações que baseiam suas economias na exploração de seus bens comuns, consolidando a dependência econômica do capital estrangeiro e voltando suas sociedades para a lógica extrativista, que não leva em conta a sustentabilidade de suas práticas, e o limite socioambiental desses recursos ou dos territórios explorados, norteando sua atuação através de um processo acumulador-explorador, que não permite a redução de seu ritmo.

O modus operandi da mineração transnacional moderna, tem como base a degradação da vida coletiva, destruição dos territórios e à violação sistemática dos direitos das populações que habitam os locais explorados, emulando a violência colonial originária que pode ser observada a partir de Potosí:

Dali se abre um trajeto no qual as violências se diversificam e as matanças se reproduzem ciclicamente, enquanto o sujeito moderno (o conquistador, em particular) vai subindo novos degraus na escala de cobiça e crueldade, amálgama mineiro da razão colonial, selado sob a liga metálica do ouro e da prata com chumbo e ferro" (ARÁOZ, 2013, p.18).

Os países da América Latina, vivem desde a década de 1990 uma reconfiguração política, com governos pautando seus projetos de poder, baseados, como na maior parte de nossa História, em um ethos eurocêntrico de desenvolvimento nacional. O modelo neoliberal ${ }^{7}$ de exploração dos recursos naturais e reprimarização das economias latino-americanas ${ }^{8}$ teve um papel central nessa mudança. No Brasil a neoliberalização econômica e social foi

\footnotetext{
${ }^{4}$ Para além das zonas geográficas as regiões tidas como centrais, dentro desse sistema, se constituem assim pois dominam os processo de exploração e concentração de riqueza, sendo por sua vez as regiões exploradas tidas como periféricas.

${ }^{5}$ Filósofo argentino exilado desde 1975 no México, sua atuação se concentra na crítica ao pós-modernismo através da defesa de um novo momento denominado transmodernidade, entendido como radical ruptura com o eurocentrismo estruturante tanto da modernidade, como da pós-modernidade.

${ }^{6}$ Economista e político equatoriano, que reivindica os direitos da natureza e o buen vivir, percebido como a construção de uma sociedade cujo desenvolvimento não esteja baseado nem na destruição sistemática dos recursos naturais nem na exploração do homem por homem.

${ }^{7}$ Entendemos neoliberalismo como políticas de liberalização econômica, que são empreendidas por meio de cortes de despesas governamentais, desestatização de empresas nacionais e adoção de políticas de austeridade fiscal, a fim de reforçar economicamente o setor privado.

8 Diminuição da exportação de produtos manufaturados em consequência do aumento das exportações de commodities (PIERRE, 2016).
} 
promovida nos governos democráticos de Fernando Collor de Mello (1990-1992), Itamar Franco (1992- 1995) e Fernando Henrique Cardoso (1995-2003), conservando os projetos no país apesar da alternância de poder. Os governos progressistas do Partido dos Trabalhadores (2003-2016), estabeleceram programas desenvolvimentistas que mantiveram a subordinação do país às linhas anteriores. Neste sentido pensou-se a integração da Amazônia ao mercado internacional, como uma região que pode ser explorada e consumida pelo grande capital, ignorando sistematicamente os desejos das populações locais, visando apenas a exploração de seus recursos naturais para as grandes indústrias, sendo esse processo ampliado em um contexto de reprimarização da economia.

A mineração durante os anos 1990 se expandiu, pautada no aumento do preço do ouro, já na década de 2000 a demanda por matéria prima aumentou com o crescimento econômico de países como Brasil, China e Índia, além dos mercados já estabelecidos da Europa e dos Estados Unidos da América, gerando assim, clima favorável para economias primário-exportadoras dirigidas por governos interessados em maior crescimento económico a curto prazo (SVAMPA, 2012, p. 81).

O eixo econômico dos países latino-americanos têm um caráter de colonialidade, que está presente no padrão de poder hoje hegemônico. O cientista social peruano Aníbal Quijano 9 (2005, p.107), defende que o atual padrão de poder hegemônico foi formado durante a colonização da América, tendo três elementos principais: a colonialidade do $\operatorname{poder}^{10}$, o capitalismo e o eurocentrismo.

Esses elementos integram o eixo colonial/moderno, ao qual os países da América Latina continuam interligados, mesmo sendo independentes politicamente, uma vez que as elites soberanas dos países colonizados, são dominantes em seus territórios, mas são dominadas na articulação dos poderes globais. O conceito de colonialidade será complementado pelo de hegemonia, permitindo melhor compreensão do processo que estamos estudando. Para referenciar o conceito supracitado, utilizaremos os trabalhos do filósofo italiano Antonio Gramsci (1978), que investiga as relações sociais, políticas e econômicas de exploração de um grupo social sobre outro, no qual o grupo subordinado adota a concepção do mundo dos dominantes, essa hegemonia cultural que produz a homogeneização do pensamento, é sustentada pelo convencimento que os grupos dominantes obtêm dos dominados: Seja pela esfera de consenso demonstrando que o interesse desses grupos é o interesse de toda a sociedade, podendo ser observados no eurocentrismo, e na adoção do discurso hegemônico do mercado pró-mineradoras, de que a expansão da mineração é um fator fundamental para o desenvolvimento de todos os setores da sociedade; como também pelo poder de coerção, inclusive armado, do grupo dominante que mantém a sujeição sobre os demais, podendo ser observado na militarização de zonas de conflitos territoriais e na criminalização dos movimentos antimineração.

\section{AMAZÔNIA BRASILEIRA}

A Amazônia é uma floresta tropical transnacional que se estende entre as fronteiras de nove nações: Brasil, Bolívia, Colômbia, Equador, Guiana, Peru, Suriname, Venezuela e o território ultramarino da Guiana Francesa. Dentro da lógica desenvolvimentista extrativista, a floresta amazônica é vista como uma reserva de valor, de lá serão extraídos os recursos naturais que servem de base para as grandes indústrias do Norte global.

\footnotetext{
${ }^{9}$ Sociólogo peruano que se dedicou aos estudos decoloniais. Tais estudos sublinham o peso da colonialidade nas relações de poder na América Latina, calcada nas relações raciais, nas quais o predomínio do que se entende por raça branca ocidental é naturalizado.

${ }^{10}$ Classificação social da população mundial de acordo com a ideia de raça, uma construção eurocêntrica que expressa a experiência da dominação colonial.
} 
O historiador paraense César de Souza (2018, p.22) argumenta que a questão Amazônica é formada por olhares de fora, visando apenas atender as demandas do mercado externo. A maior parte das populações locais são ignoradas nas tomadas de decisões, excetuando-se uma pequena parcela das elites políticas e econômicas, mesmo que os projetos tenham um grande impacto socioambiental no estilo de vida das comunidades afetadas pelos projetos, afinal nos séculos XIX e XX, a narrativa homogênea exercida pelo aparelho de Estado brasileiro era de que a região amazônica era um "grande vazio demográfico". A região, teoricamente vazia, torna-se atrativa para migrações populacionais, rumo a projetos extrativistas:

Fossem as propostas da era Vargas (1930-1945), de colonização ou retomada da produção seringueira, fossem as do regime empresarial-militar (1964-1985), cujo maior símbolo seria a rodovia Transamazônica, ou mais recentemente a hidrelétrica de Belo Monte, (há dezenas em projeto), tudo parece pensado como se ninguém morasse na imensa área marcada pela floresta equatorial (RIBEIRO, p. 101).

Poderíamos associar esse fenômeno ao conceito de "colonialismo interno" proposto pelo sociólogo mexicano Pablo González Casanova ${ }^{11}$ (2006), que reflete a colonialidade de poder reproduzida no interior do Estado-nação, criando uma hierarquia interna de regiões desenvolvidas/subdesenvolvidas. No caso brasileiro, essa condição é evidenciada na visão homogeneizante do sul e sudeste, centro econômico do país, sobre as demais regiões, a colonialidade do poder só admite uma única escala de desenvolvimento universal, espelhada no modelo eurocêntrico. Logo os territórios tidos como desenvolvidos são aqueles que mais se aproximam do estágio econômico das nações colonizadoras, legitimando as relações de dominação impostas durante a colonização.

\subsection{CONTEXTO HISTÓRICO DA EXPLORAÇÃO SOBRE A REGIÃO}

A exploração da região amazônica se divide nas últimas décadas em três esferas: geração de energia através da expansão das hidrelétricas; logística, em obras de transporte de commodites; e mineração, a Amazônia é rica em minérios que atraem grandes empresas e garimpeiros individuais (CHAVES; SOUZA, 2018, p.4). Segundo o geógrafo Carlos Walter Porto-Gonçalves ${ }^{12}$ em seu artigo Amazônia enquanto acumulação desigual de tempos: Uma contribuição para a ecologia política da região $(2015$, p.81), o atual ciclo de exploração dos recursos naturais amazônicos se iniciou na década de 1960 com uma série de grandes projetos organizados pelo regime empresarial-militar brasileiro (1964-1985), baseado na inauguração de grandes estradas amazônicas, tendo como marco a Transamazônica (1971) que buscava integrar à região ao restante do país, facilitando o escoamento de produtos para outros pontos do território nacional e ao exterior.

A Iniciativa para a Integração da Infraestrutura Regional Sul-Americana (IIRSA) ${ }^{13}$ teve como subproduto o Programa de Aceleração do Crescimento (PAC) organizado pelos governos do PT no Brasil, esse programa teve como símbolo a Usina Hidrelétrica de Belo Monte (UHE), que provocou um grande impacto ambiental às populações que vivem entorno do rio Xingu. A construção de Belo Monte seguiu o processo de colonialismo interno, ignorando as populações

\footnotetext{
${ }^{11}$ Sociólogo mexicano com amplos estudos sobre colonialismo, especialmente a noção de colonialismo interno, que expressa relações de dominação de uma região sobre outra num mesmo país.

${ }^{12}$ Geógrafo brasileiro com estudos acerca da Geografia Social, é Professor Titular da Universidade Federal Fluminense (UFF) e Coordenador do LEMTO - Laboratório de Estudos de Movimentos Sociais e Territorialidades.

${ }^{13}$ Trata-se de uma proposta surgida no início dos anos 2000 no sentido de integrar redes de transportes, energia e comunicações nos doze países independentes da América do Sul.
} 
locais e servindo como um projeto pautado para o desenvolvimento da infraestrutura de integração da região, ao mercado capitalista globalizado.

A inauguração do empreendimento hídrico em 2016, marcou o último compromisso oficial de Dilma Rousseff (2011-2016) como presidente do Brasil, que naquele momento já sofria com o avançar do processo de impeachment que iria removê-la do cargo poucos dias após o evento. No discurso proferido pela mandatária, podemos observar a narrativa hegemônica desenvolvimentista, Belo Monte é tratada como um legado ao povo de Altamira e do Xingu, pois permitiria que empresas privadas estabelecessem seus negócios na região explorando os recursos minerais, tendo na hidroelétrica sua base energética necessária para realizar grandes empreendimentos extrativistas ${ }^{14}$. Esse é um legado antigo, anterior as obras do PAC, da Transamazônica ou dos empreendimentos de colonização getulistas, esse é o legado de Potosí, a exploração e sacrifício dos povos e dos territórios, a naturalização da barbárie. Nas palavras de Horácio Machado Aráoz, ${ }^{15}$ esse é um traço da colonialidade sendo "O colonialismo em estado de naturalização" (2020, p.258).

Nesse contexto os protestos de moradores locais, ambientalistas e dos povos originários são ignorados, em carta aberta o movimento Xingu vivo para sempre ${ }^{16}$ acusa Dilma de submeter a região ao mesmo plano extrativista que o regime empresarial-militar ${ }^{17}$, vemos que as narrativas contra-hegemônicas de movimentos sociais locais, captam o fenômeno da mineração transnacional moderna, como algo que transpassa governos; os políticos no poder mudam, mas a orientação político-econômica segue sendo norteada por ideais desenvolvimentistas eurocêntricos, conectados a colonialidade do poder que veem a Amazônia como um local à ser explorado. Essa continuidade fica evidente quando analisamos as propostas do governo de Michel Temer (2016-2018), sucessor de Dilma na presidência, as mesmas foram compiladas no programa denominado "Ponte para o Futuro", visando a continuidade das medidas de expansão da infraestrutura, a fim de comportar grandes empreendimentos na região. A ponte para o futuro, vem diretamente de 1492.

Se quisermos ultrapassar essa visão colonial, será necessário adotar uma perspectiva capaz de notar a multiculturalidade e a complexidade da região amazônica e de seus povos:

\begin{abstract}
Ainda hoje cerca de 180 línguas são faladas na Amazônia, um dos maiores patrimônios culturais do Brasil e da humanidade. Assim, sobre a Amazônia, além de referirmos a biodiversidade é importante atentarmos para a diversidade cultural existente na região e nos acostumarmos com a ideia de que existem Amazônias e amazônidas. Pensar uma região com essa extensão, com essa complexidade, como se fosse homogênea implica tornar invisíveis esses outros povos e suas territorialidades ancestrais/atuais. (PORTO-GONÇALVES, 2015 p.70).
\end{abstract}

Os povos que habitam a Amazônia não podem ser encaixados em uma categoria definitiva, tão pouco tem necessidades e pensamentos únicos, as ideias desenvolvimentistas em seu âmago tendem a dividir o mundo na dualidade colonial entre atrasados e desenvolvidos. Uma visão limitada para suprir os anseios das diversas comunidades amazônidas.

\title{
2 VOLTA GRANDE DO XINGU E CONGA
}

\footnotetext{
${ }^{14}$ Ver em: BRUM, Eliane. Dilma compôs seu réquiem em Belo Monte. Jornal El País Brasil, São Paulo, 10 de maio de 2016. Disponível em: https://brasil.elpais.com/brasil/2016/05/09/opinion/1462804348_582272.html. Acesso em: 26 jul. 2021.

${ }^{15}$ Filósofo argentino, professor da Universidade Nacional de Catamarcar e pesquisador do Conselho Nacional de Pesquisas Científicas e Técnicas - CONIC.

${ }^{16}$ Ver em: MOVIMENTO XINGU VIVO PARA SEMPRE. Fazem com você o que você fez conosco; mas nem assim, Dilma. | Xingu Vivo. Altamira, 05 de maio. de 2016. Disponível em: https://xinguvivo.org.br/2016/05/05/fazem-com-voce-o-que-voce-fez-conosco-mas-nem-assim-dilma/. Acesso em: 26 jul. 2021.

${ }^{17}$ Dilma é uma ex-guerrilheira que foi presa e torturada durante a ditadura.
} 
Neste ponto vamos fazer uma abordagem comparativa entre o projeto de mineração brasileiro Volta Grande do Xingu e o peruano Conga, procurando demonstrar sua conexão com o fenômeno da mineração transnacional moderno, a transterritorialidade de seus impactos ambientais e analisar de que forma atuam o poder hegemônico em suas esferas de consenso e coerção.

O estudo da mineração no Brasil e no Peru, vai levar em conta as noções de colonialidade já expostas nesse artigo, que entendem ambas como nações componentes da América Latina moderna, formadas a partir de uma estrutura de origem e caráter colonial, sendo essa estrutura mais duradoura do que o colonialismo em cuja matriz foi concebida. A validade da comparação entre as duas nações latino-americanas, ocorre também por suas interinfluências históricas ${ }^{18}$ (PRADO, 2005, p. 15). Acredito que ao realizarmos um trabalho de História Comparada, de forma crítica poderemos desenvolver um trabalho que enriqueça a produção historiográfica brasileira.

\subsection{IMPACTOS AMBIENTAIS TRANSNACIONAIS}

Volta Grande do Xingu é um empreendimento que busca ser a maior mina de exploração de ouro a céu aberto, no Brasil. Esse projeto, encontrou a resistência de ambientalistas, moradores das comunidades e terras indígenas, que irão sofrer com os impactos ambientais, na região de Altamira ${ }^{19}$. Os mesmos já se ressentiram, anteriormente, com a construção da rodovia Transamazônica (1970) e da Usina Hidrelétrica de Belo Monte (2011), que fica também no Estado do Pará, localizando sua ação na bacia do rio Xingu que nasce no Mato Grosso e se torna afluente do rio Amazonas, diversas terras indígenas se encontram ao seu redor e desenvolvem seu modo de vida a partir deste rio. É importante ressaltar que é nessa mesma região do Pará, onde foi estabelecido o emblemático garimpo de Serra Pelada ${ }^{20}(1979-1992)^{21}$, que chegou a ser o maior garimpo a céu aberto ${ }^{22}$ do mundo na década de 1980.

Esse projeto minerador conta com a participação do capital da empresa canadense Belo Sun Ltda, subsidiária da Belo Sun Mining Corporation (empresa de capital aberto que compõe o grupo Forbes \& Manhattan INC), sua sede regional fica no município de Senador José Porfírio, no Estado do Pará. O empreendimento está com a Licença de Instalação (LI) suspensa pela Justiça desde 2017, devido à não realização da consulta pública às Terras Indígenas (TI) prevista em lei em regulamentos internacionais.

O Peru também está inserido no já mencionado contexto de neoliberalização e reprimarização econômica das nações latino-americanas, em meados de 1992, ano em que desfechou um golpe de Estado fechando o congresso nacional, a ditadura Alberto Fujimori (1990-2000) produziu profundas mudanças neoliberais na economia peruana, que afetaram as estruturas sociais no país amazônico-andino. O neoliberalismo prosseguiu nos governos de Alejandro Toledo (2001-2006), Alan García Pérez (2006- 2011), Ollanta Humala (2011-2016) e Pedro Pablo Kuczynski (2016-2018) a mineração foi percebida pelos diversos governos como bastião dos planos econômicos desenvolvimentistas peruanos:

\footnotetext{
${ }^{18}$ Cito aqui as de maior destaque: Colonização ibérica, preeminência dos ingleses na economia, e posteriormente dos estadunidenses, formação dos estados nacionais, economias primário-exportadoras e recentemente a presença econômica de investimentos brasileiros na economia peruana.

${ }^{19}$ Sudeste do Pará.

${ }^{20} \mathrm{O}$ garimpo de serra pelada contou com investimentos da multinacional brasileira Vale S.A. (antiga estatal)

${ }^{21}$ A mina de ouro da vila de Serra Pelada continua fechada, porém os garimpeiros podem explorar os recursos auríferos em uma área próxima.

${ }^{22}$ Nos referimos a atividade realizada em rochas aflorantes ou aluviões.
} 
Posto que esta neoliberalização da sociedade se tratava principalmente de investimentos em mineração e hidrocarbonetos, se reafirmou e produziu a histórica dependência econômica do Peru e da exploração de seus bens comuns, consolidandoo como uma sociedade extrativista por excelência. (HOETMER, 2013, p.20, tradução nossa $)^{23}$

O projeto Conga estabelece uma área de exploração de ouro e cobre na região de Cajamarca, pela empresa Yanacocha (com capital de uma empresa estadounidense Newmont Mining Corp), se concluído Conga será o maior empreendimento minerador da América Latina. Em caso semelhante ao Brasil, a luta contra a mineração converge com a oposição aos projetos de construção de hidrelétricas no rio Marañón, uma vez que, a crescente demanda por energia elétrica pelas mineradoras, está diretamente ligada a estes projetos visando abastecer aquelas. O complexo de hidrelétricas conhecido como "Chadin" ${ }^{24}$, que incluem Rio Grande 1, Rio Grande 2 e Chandín 2, fazem parte de um plano para a edificação de 20 represas ao longo do rio Marañón. Em 2010 um acordo de exportação de energia entre os governos de Brasil e do Peru, levou a ativação desse projeto elaborado pela Eletrobrás ${ }^{25}$, que é operado pelo conglomerado transnacional brasileiro Odebrecht.

O rio Marañón corta os Andes, sendo considerado sagrado para povos que cultuam a deusa da terra Pachamama, justamente pela sua capacidade de irrigação e fertilização do solo. Esse rio andino é um afluente do Amazonas, ele percorre a região norte do Peru atravessando uma área de fusão de dois biomas: o planalto dos andes e a floresta tropical Amazônica. Podemos concluir então que tanto Conga quanto o complexo hídrico Chandín, vão provocar um impacto ambiental em larga escala, transcendendo o território do Peru e o bioma de Cajamarca, até atingir a floresta amazônica e os territórios alcançados pelo rio Amazonas em ambos os países, drenando uma fração de sua capacidade hídrica. A natureza permanece em estado de equilíbrio, interconectando diferentes biomas e territórios, logo, quando esse equilíbrio é prejudicado, pelos os impactos ambientais da mineração transnacional moderna, o desequilíbrio natural transcende os territórios nacionais.

A interconexão entre Volta Grande e Conga, não está somente no plano ambiental, como também no modus operandi da mineração transnacional moderna. Como já foi exposto na primeira parte deste artigo, o poder hegemônico atual é calcado na colonialidade de poder, diante disso vamos explorar como as esferas de consenso e de coerção atuam na implementação de ambos os projetos de mineração.

\subsection{ESFERA DE CONSENSO}

A esfera de consenso exercida pelo poder hegemônico, pode ser observada na homogeneização do conceito de desenvolvimento universal, que perpetua a lógica eurocêntrica, na qual os países colonizadores são continuamente associados como desenvolvidos e por consequência os países colonizados são taxados como subdesenvolvidos.

Segundo o trabalho Los imaginários que sostienen la expansión minera en los Andes de Rodríguez-Carmona e Castro (2013, p.34) no Peru o discurso de combate à pobreza foi assimilado pela direita peruana e pelas grandes corporações de minério, centralizando os debates em torno da mineração, entre: Os campesinos retratados como atrasados, agricultores

\footnotetext{
${ }^{23}$ Original em espanhol: Puesto que esta neoliberalización de la sociedad peruana se trataba principalmente de inversiones mineras y de hidrocarburos, se confirmó y profundizó la histórica dependencia económica del Perú de la explotación de sus bienes comunes, consolidando al Perú como una sociedad extractivista por excelencia.

${ }^{24}$ No caso de Chadín a construtora brasileira conseguiu a concessão do governo e a licença ambiental pelo Ministério de Minas e Energia peruano, mas não a licença social, que da forma que é prevista em lei, deve passar por uma consulta pública às comunidades tradicionais que terão suas terras afetadas.

${ }^{25}$ Empresa de capital aberto, controlada de forma acionária pelo Governo brasileiro.
} 
de subsistência que seriam incapazes de fazer a economia do país se desenvolver; e as mineradoras, lançadas à posição de líderes do progresso, modernizadores sociais que permitiriam que suas atividades econômicas modificassem a vida no interior do país, levando tecnologia e renda.

O presidente Alan García (2006-2011), em 2007 escreveu um artigo no importante jornal El Comercio, El síndrome del perro del hortelano ${ }^{26}$, relacionando os campesinos de origem nativa a cachorros em hortaliças, que não comem e nem deixam os outros comerem. $\mathrm{Ou}$ seja, ocupam uma terra rica em recursos extrativistas, não exploram economicamente esses recursos e nem permitem que outros explorem. O próprio lema do Ministério de Minas e Energia do Peru é "Perú: un país minero", a síntese dessa ideia do país andino como pátria mineradora pode ser observado no discurso de Alan García em 20 de julho de 2007, na inauguração de Cerro Lindo da companhia de mineração Milpo "Podemos desenvolver muitas mais minas. O Peru é um país que Deus assinalou como país minero e pôr-se contra esse desígnio é lutar em vão...” (ARÁOZ, 2020, p. 78).

Discurso similar ao adotado pelo aparelho de Estado brasileiro para justificar a instalação de grandes projetos desenvolvimentistas, ditos como um bem para toda a população, como a promessa de royalties e multiplicação de empregos que beneficiaram os moradores das comunidades afetadas, o prefeito Dirceu Biancardid (2016-2020, e reeleito em 2021 para governar até 2024) do município de Senador José Porfírio/ $\mathrm{PA}^{27}$, é uma das autoridades que defendem o projeto, incitando um enfrentamento contra os moradores antimineração, tidos como barreiras ao desenvolvimento nacional. Em fala pública em 2017, o prefeito defendeu essa ideia de mineração como progresso local: "A empresa tem projeto, a empresa tem condicionantes pro povo, vai gerar emprego pro nosso município, vai ter estrada boa, vai ter mais escolas, vai ter melhora pro nosso município" (BRUM, 2017).

\subsection{ESFERA DE COERÇÃO}

Já a escala de coerção pode ser vista através do cerceamento de fala das populações tradicionais, criminalização dos movimentos sociais, remoções forçadas e perseguições.

No Peru desde 2002 uma série de leis e normas foram criadas para reprimir os protestos sociais como a Lei $N^{\circ} 29166^{28}$ que permite o uso de armas de fogo pelas forças armadas para o "controle interno". A criminalização dos movimentos sociais demonstra que o aparelho de Estado peruano está comprometido com a viabilização dos projetos mineiros, não importa o custo social. É importante acrescentar que entre 2004 e 2013, segundo o relatório da Comissão Interamericana de Direitos Humanos (CIDH, 2015) somente em Cajamarca, protestos antimineradoras deixaram 11 mortos e 282 feridos.

O discurso de criminalização é articulado entre a grande mídia que tem ligações com empresas ligadas a mineração ${ }^{29}$ e setores políticos de extrema direita ${ }^{30}$, sendo construído na

\footnotetext{
${ }^{26}$ Ver em: PERÉZ, Alan García. El síndrome del perro del hortelano. El Comercio, Lima, 28 de out. de 2007. Disponível em: https://indigenasdelperu.files.wordpress.com/2015/09/26539211-alan-garcia-perez-y-el-perrodelhortelano.pdf. Acesso em: 26 jul. 2021.

${ }^{27}$ Ver em: BRUM, Eliane. Senador José Porfírio, Pará, Amazônia: altíssimo risco. Jornal El País Brasil, São Paulo, 11 de dez $2017 . \quad$ Disponível https://brasil.elpais.com/brasil/2017/12/11/opinion/1512997340_266770.html. Acesso em: 26 jul. 2021

${ }^{28}$ Ver em: PERU. Ley que establece reglas de empleo de la fuerza por parte del personal de las fuerzas armadas en el territorio nacional. Ley $\mathbf{N}^{\circ} \mathbf{2 9 1 6 6}$ de 19 de dez. 2007. Disponível em: https://leyes.congreso.gob.pe/Documentos/Leyes/29166.pdf. Acesso em: 29 de dez. 2020.

${ }^{29}$ Caso do jornal El Comercio, no qual os donos têm estreitas ligações com empreiteiras ligadas a projetos de mineração, como a transnacional brasileira Odebrecht (DURAND,2018, p. 107).

${ }^{30}$ Esse discurso pode ser observado recorrentemente em vídeos vinculados a canais da extrema direita peruana na internet (SANTISTEBAN, 2013, p. 443).
} 
tentativa de ligar os movimentos antimineração a organizações criminosas, como o narcotráfico que supostamente financiava marchas contrárias às ações mineradoras, como a famosa "Conga no va", permitindo assim que diversos governantes peruanos fundamentassem suas ações repressivas como "combate ao narcotráfico":

\begin{abstract}
O uso da violência pelo Estado, que é legitimado para cumprir os objetivos de ordem e segurança, é uma forma de recuperar a ordem das coisas em que os seres das terras voltam a ser mero recurso a ser explorado, principalmente no caso de conflitos mineiros. O estado de exceção reforça e constrói o mito hegemônico, a história que se deseja manter linear, "Peru: país mineiro". (PEÑAFIEL, 2016, p. 98).
\end{abstract}

No Brasil, a coerção pode ser observada na tentativa de deslegitimação dos povos originários como atingidos, a empresa canadense Belo Sun recorreu diversas vezes ao judiciário na tentativa de impedir que fosse realizada uma consulta pública às populações indígenas afetadas por Volta Grande. A empresa também utiliza uma tática de pressão usada por empresas ligadas ao setor de mineração em Cajamarca $^{31}$, mesmo sem licença de construção elas adquirem terras públicas, com a finalidade de minar a articulação entre os moradores locais contrários à mineração. Outra estratégia de pressão, é a proibição da extração de ouro de maneira artesanal do leito do rio Xingu, estrangulando economicamente as comunidades tradicionais de Volta Grande que tem na extração artesanal do ouro uma de suas principais fontes de renda (CHAVES; SOUZA, 2018, p.7).

A coerção dos movimentos sociais contrários à mineração também é exercida por representantes públicos, o prefeito de Senador José Porfírio, utiliza o poder do aparelho de Estado municipal para perseguições, em 2017 ele invadiu o auditório da Universidade Federal do Pará (UFPA), impediu o debate acadêmico referente a instalação de Volta Grande e trancou estudantes e professores dentro da sala ${ }^{32}$. Podemos reconhecer que existe, em ambos os casos apresentados, uma articulação entre as esferas hegemônicas de consenso e coerção, uma vez que medidas de coerção são sistematicamente adotadas contra indivíduos ou comunidades que não aderem ao consenso pró-mineradoras.

\title{
3 CONCLUSÃO
}

Ao estudarmos os projetos de mineração Conga e Volta Grande, buscamos identificar como atuam os elementos de colonialidade presentes em todas as suas estruturas. Sendo possível observar que eles são implementados por uma lógica desenvolvimentista, que se vale do discurso eurocêntrico produzido na colonização, de divisão entre atrasados e desenvolvidos, sendo os primeiros todos que se integram de uma forma subordinada a produção capitalista, no Peru são os campesinos de origem nativa e os moradores da região de Cajamarca, que sofrerão os impactos ambientais em suas terras ao longo do rio Marañón, e no Brasil os ribeirinhos, pequenos agricultores, extrativistas e as terras indígenas Arara da Volta Grande do Xingu, Paquiçamba ${ }^{33}$ e Itun/Itatá, ou seja, todas as comunidades que vivem em torno do Rio Xingu.

Os países latino-americanos enquanto adotarem esse modelo primário-exportador ficarão reféns das flutuações do mercado, uma vez que as empresas de extração de minérios são de capital estrangeiro e buscam atender demandas de mercados externos, os países exportadores ficam dependentes que o consumo de bens primários se mantenha sempre elevado, não podendo forçar a produção desses bens, pois correm o risco de que com o aumento da

\footnotetext{
${ }^{31}$ Em entrevista à Agência Pública (2015) à líder comunitária dos municípios de Huanabamba e Celendín Aurora Araujo acusa a empreiteira transnacional Odebrecht de infiltrar pessoas nas comunidades e forçar a compra de terras, na tentativa de desmobilizar as articulações internas.(GOYZUETA, 2015)

${ }^{32}$ Ver Nota 24.

${ }^{33}$ A terra indígena de Paquiçamba se encontra a menos de 9,5 km do local de construção de Volta Grande.
} 
oferta, o valor do produto diminua. Na definição de Alberto Acosta $(2009$, p.11) essa é a "A maldição da abundância", que permeia nosso objeto de estudo, demonstrando a incapacidade das nações colonizadas em se desassociar desse modo produtivo de exploração dos próprios recursos naturais, enfraquecendo suas democracias e impedindo o exercício pleno da cidadania por muitos de seus cidadãos, vistos como barreiras ao crescimento comercial.

Por fim é importante destacar a luta e resistência dos movimentos sociais antimineração no Brasil e no Peru, movimentos esses que lutam pela preservação de seu modo de vida, oferecendo uma visão contra-hegemônica da difundida pelos patronos da mineração que caminha para um ideal desenvolvimentista específico, sem levar em conta o progresso cultural de comunidades locais. Um espelho que nunca vai refletir a realidade dos povos latinoamericanos como um todo.

\section{REFERÊNCIAS}

ACOSTA, Alberto. La Maldición de la abundancia. Quito: CEP, Swissaid e Abya-Yala, 2009.

ARAÓZ, Horácio Machado. Mineração, genealogia do desastre: o extrativismo na América como origem da modernidade. São Paulo: Editora Elefante, 2020.

BRUM, Eliane. Dilma compôs seu réquiem em Belo Monte. Jornal El País Brasil, São Paulo, 10 de maio de 2016. Disponível em: https://brasil.elpais.com/brasil/2016/05/09/opinion/1462804348_582272.html. Acesso em: 26 jul. 2021.

BRUM, Eliane. Senador José Porfírio, Pará, Amazônia: altíssimo risco. Jornal El País Brasil, São Paulo, 2017. Disponível em:

https://brasil.elpais.com/brasil/2017/12/11/opinion/1512997340_266770.html. Acesso em: 26 jul. 2021.

\section{COMISIÓN INTERAMERICANA DE DERECHOS HUMANOS. Informe de la Relatoría Especial para la libertad de expresión. Washington: CIDH, 2015.}

DURAND, Francisco. Odebrecht: la empresa que capturaba gobiernos. Lima: Pontificia Universidad Católica del Perú, 2018.

ECHAVE, José De; DIEZ, Alejandro. Más allá de Conga. Lima: RedGE, 2013.

GOYZUETA, Verónica. Eles que comam ouro! Agência Pública, São Paulo, 19 de ago. de 2015. Disponível em: https://apublica.org/2015/08/eles-que-comam-ouro. Acesso em: 29 de dez. 2020.

GRAMSCI, Antonio. Maquiavel, a Política e o Estado moderno. Rio de Janeiro: Civilização Brasileira, 1978.

HOETMER, Raphael. Introducción. In: HOETMER, Raphael (Ed.), et al. Minería y movimientos sociales en el Perú: instrumentos y propuestas para la defensa de la vida, el agua y los territorios. Lima: Programa Democracia y Transformación Global, 2013, p. 19- 28. 
MOVIMENTO XINGU VIVO PARA SEMPRE. Fazem com você o que você fez conosco; mas nem assim, Dilma... | Xingu Vivo. Altamira, 05 de maio. de 2016. Disponível em: https://xinguvivo.org.br/2016/05/05/fazem-com-voce-o-que-voce-fez-conosco-mas-nemassim-dilma/. Acesso em: 26 jul. 2021.

PEÑAFIEL, Adriana Paola P. Desenhos e relações e desenvolvimento: conflitos em torno da mineração na região andina de Cajamarca, Peru. 229 f. Tese (Doutorado em Desenvolvimento Rural)- Universidade Federal do Rio Grande do Sul, Porto Alegre, 2016.

PERÉZ, Alan García. El síndrome del perro del hortelano. El Comercio, Lima, 28 de out. de 2007. Disponível em: https://indigenasdelperu.files.wordpress.com/2015/09/26539211-alangarcia-perez-y-el-perro-delhortelano.pdf. Acesso em: 26 jul. 2021.

PERU. Ley que establece reglas de empleo de la fuerza por parte del personal de las fuerzas aramdas em el territorio nacional. Ley $\mathbf{N}^{\circ} 29166$ de 19 de dez. 2007. Disponível em: https://leyes.congreso.gob.pe/Documentos/Leyes/29166.pdf. Acesso em: 29 de dez. 2020.

PERU. Ley que establece reglas de empleo de la fuerza por parte del personal de las fuerzas aramdas em el territorio nacional. Ley $\mathbf{N}^{\circ} 29166$ de 19 de dez. 2007. Disponível em: https://leyes.congreso.gob.pe/Documentos/Leyes/29166.pdf. Acesso em: 29 de dez. 2020.

PIERRE, Salama. Reprimarização sem industrialização, uma crise estrutural no Brasil/ Reprimarization without industrialization, a structural crisis in Brazil. Argumentum, v. 8, p. 127, 2016.

PORTO-GONÇALVES, Carlos Walter. Amazônia enquanto acumulação desigual de tempos: Uma contribuição para a ecologia política da região. Revista Crítica de Ciências Sociais, Coimbra, n. 107, p. 63-90, 2015. Disponível em: https://doi.org/10.4000/rccs.6018. Acesso em: 26 jul. 2021.

PRADO, Maria Ligia Coelho. Repensando a história comparada da América Latina. Revista de História Comparada, Rio de Janeiro, n. 153, p. 11-33, 2005.

QUIJANO, Aníbal. Colonialidade de poder, eurocentrismo e América Latina. In: LANDER, Edgardo (Org.). Colonialidade do Saber: eurocentrismo e ciências sociais perspectivas latino-americanas. Buenos Aires: CLASCO, 2005.

RIBEIRO, Vanderlei Vazelesk. Na selva reina a lei da selva: Reflexões sobre a Amazônia peruana (1821-2009). In: ROMANI, Carlos (Org.), et al. Fronteiras e Territorialidades: miradas sul-americanas da Amazônia à Patagônia. São Paulo: Editora Intermeios, 2019, p. 101-123.

RODRÍGUEZ-CARMONA, Antonio; CASTRO, Miguel. Los imaginários que sostienen la expansión minera em los Andes. In: HOETMER, Raphael (Ed.), et al. Minería y movimientos sociales en el Perú: instrumentos y propuestas para la defensa de la vida, el agua y los territorios. Lima: Programa Democracia y Transformación Global, 2013, p. 31- 45.

SANTISTEBAN, Rocíon Silva. Porque son perros: protestas, discursos autoritarios y industrias extractivas. El caso Conga. In: HOETMER, Raphael (Ed.), et al. Minería y movimientos sociales en el Perú: instrumentos y propuestas para la defensa de la vida, el 
agua y los territorios. Lima: Programa Democracia y Transformación Global, 2013, p. 435453.

SOUZA, César Martins de. A região dos desejos e das aventuras: diálogos sobre grandes projetos de integração e desenvolvimento na Amazônia nos séculos XIX e XX. Revista Cadernos do Ceom, v. 31, n. 48, p. 21-29. 2018. Disponível em:

https://doi.org/10.22562/2018.48.02. Acesso em: 26 jul. 2021.

SVAMPA, Maristella. Consenso de los commodities y megaminería. América Latina en Movimiento. Quito, n.473, 2012, p.79-105. 